Article

\title{
Ecological Conservation, Ecotourism, and Sustainable Management: The Case of Penang National Park
}

\author{
Sara Kaffashi ${ }^{1, *}$, Alias Radam ${ }^{2}$, Mad Nasir Shamsudin ${ }^{1}$, Mohd Rusli Yacob ${ }^{1}$ and \\ Nor Hanim Nordin ${ }^{3}$
}

1 Faculty of Environmental Studies, Universiti Putra Malaysia, 43400 UPM Serdang, Selangor, Malaysia; E-Mails: mns@upm.edu.my (M.N.S); mroy@upm.edu.my (M.R.Y)

2 Department of Management and Marketing, Faculty of Economics and Management, Universiti Putra Malaysia, 43400 UPM Serdang, Selangor, Malaysia; E-Mail: alias@putra.upm.edu.my

3 Faculty of Economics and Management, Universiti Putra Malaysia, 43400 UPM Serdang, Selangor, Malaysia; E-Mail: ha_namesg@yahoo.com

* Author to whom correspondence should be addressed; E-Mail: sarakafashi@gmail.com; Tel.: +60-142-366-368.

Academic Editor: Damian C. Adams

Received: 30 March 2015 / Accepted: 4 June 2015 / Published: 7 July 2015

\begin{abstract}
Penang National Park (PNP), as Malaysia's smallest national park, is one of the few naturally forested areas left on Penang Island, in Peninsular Malaysia. The main objective was to analyse users' preferences and willingness to pay to enhance improved management of PNP for the dual aim of conservation and recreation. Structural equation modelling (SEM) was used to analyse the formation of attitudes towards different aspects of PNP. Results showed that implementing enforcements with rules and regulations and imposing permits and charges on certain activities were the most influential variables of PNPs' perceptions. The results of a random parameter logit model (RPL) demonstrated that visitors placed the highest value on having adequate information about PNP, and the second-highest value on improvements in the park's ecological management. The welfare measure for improvement in management of PNP against status quo is estimated at about MYR 9. Results also showed that demand for better conservation and management of PNP is relatively price-inelastic. Simulations of the results showed, under a MYR10 admission fee, that improvement in management would have $96 \%$ of market share compared with status quo. This study concluded that visitor entrance fees can and ought to be introduced
\end{abstract}


as a means of financing conservation initiatives and possibly preventing congestion.

Keywords: conservation charge; nature based tourism; park visitor preferences; structural equation modeling; choice experiment; provision of information; willingness to pay

\section{Introduction}

National parks were established primarily to conserve and enhance natural scenery, wildlife, and cultural heritage. However, over the years this aim has slightly broadened to include education, recreation, and local poverty reduction. Nowadays, national parks all over the world are important tourist destinations. Ecotourism is a perfect example of direct monetary values provided by nature [1,2]. Increasing interests in nature-based tourism made it one of the largest and fastest growing segments of tourism industry in the last decade. However, a key consideration for managers is to be aware that achieving the dual goals of conservation and tourism requires regular assessment of tourism satisfaction and preferences to find out whether ecotourism needs are in accordance with conservation goals [3].

Based on annual reports from Malaysia's Department of Wildlife and National Parks (DWNP), the number of visitors to the protected areas of Malaysia has doubled in the past 10 years. This shows the great current demand for nature-based tourism and the need for facilities and infrastructures to support this increasing demand. Therefore, parks authorities in Malaysia need to develop facilities for visitors which minimize any possible conflicts with their conservation goals [4]. An effective approach in providing services that can balance both ecological conservation and income generation from parks is to understand and incorporate conservation goals, tourists' preferences for nature appreciation, infrastructure, and other attributes of protected areas [5]. In doing so, knowing the visitors' priorities between conservation of the ecological and biological future of a park and its tourism use is essential. Moreover, managers who must budget carefully and invest in conservation, resource management, and tourist accommodations can inform themselves about how these managerial decisions could impact their revenue through commissioning and carefully studying research on visitors' perceptions and preferences concerning natural environment protection and possible tradeoffs with recreational facilities, if budgets are tight [3].

Located on the northwestern tip of Penang Island, Penang National Park (PNP) is Malaysia's smallest national park. PNP is the only considerable natural forested areas left on Penang Island. Penang Island is considered one of the most developed places in Malaysia. In 2012, PNP and ten other protected areas under the management of the Department of Wildlife and National Parks (DWNP) attracted 1.3 million tourists, a 6.5\% increase compared with 2011. This figure, which represents a $22.5 \%$ increase compared to 2011, is evidenced by 108,276 visits to PNP (DWNP 2012). The current practice in PNP ecotourism is concentrating on "conventional carrying capacity technique" to calculate a "magic number" as a "threshold limit" [6]. Lack of enforcement of laws and regulations, encroachment of urban and agricultural land uses into the park, and lack of zoning are sources of natural environment disturbance and visitor dissatisfaction. PNP management needs to find approaches for comprehensive improvement from current conditions, which are unsatisfactory in many respects. 
Calculating the extent of resource improvements from the current conditions and how those improvements affect visitor satisfaction can inform PNP managers in their decisions whether to match visitor preferences with long-term, medium-range, and short-term park goals (if applicable) [7]. Previous studies suggested that visitor satisfaction directly affects their willingness to pay to adopt conservation programs $[1,8,9]$. Therefore, the educational mission of the park may require extra funds that some managers might not have in-house. This is where consulting with experts can inform their decision to institute an entrance fee.

There is no doubt that better achieving management goals and improving overall visitor satisfaction requires money that most often is beyond the national government's budget for such purposes [10]. GEF-UNDP funded an extensive project of "Enhancing Effectiveness and Financial Sustainability of Protected Areas in Malaysia" (2012-2019). The aim of this project is to improve management and funding for the nation's national parks. During the project period, Department of Wildlife and National Parks Malaysia (DWNP) will try to optimize, balance, and broaden its long-term management plan and share with visitors the costs of protecting protected areas of Malaysia which they are visiting [4]. At this moment, PNP only relies on the government's budget allocation, and visitor entries into the park are free. Finding strategies for a diverse revenue steam can improve the protection, maintenance, and upgrades of natural attractions of PNP, but that is another challenge for park management. Diverse source(s) of income could reduce the park's over-reliance on any one funding source. It can also help PNP to establish its financial self-sufficiency, which is beneficial for long-term sustainability of the park. For many tourist areas, charging visitors an entry fee is believed to be the only sustainable approach to self-financing, other than relying upon government budget allocations [11]. Entry fees also can help to prevent congestion by creating an entry barrier for those below the WTP threshold. However, any realistic entry fee amount must be evidence-based and match the WTP of the respondents [12].

A choice experiment can help to disaggregate preferences and tradeoffs among different attributes of the park, including price. It can inform PNP managers about the relative value of each of the different attributes being evaluated. Estimation of visitors' marginal WTP and compensated surplus can provide valuable information on whether or not to introduce an admission fee and what such an admission fee should be. Discovering visitors' preferences and their most favored recreational uses of the park can help park managers prioritize the improvement of park features which best support the preserve financially, without which the resource could die from inadequate funding [7,13]. Several studies applied choice experiment techniques to gather information on visitors' preferences (e.g., [3,7,14-23]. These studies further concluded that respondents are ready to pay to gain maximum utility from their preferred activities.

The aim of this study was to discover how visitors might differentially value and thus be willing to trade off management and recreational aspects of PNP, including restricted access to some areas and packaged and/or layered pricing, in the form of an admission fee, leaving open the possibility of additional fees for other premium uses of the park. Specifically, this study will present the use of a structural equation modelling (SEM) and choice experiment (CE) as mechanisms to analyze preferences and WTP of tourists in relation to the future development of PNP. Results of this study could be useful on obtaining values of different aspects of the park (from the viewpoint of either conservation or tourism) from respondents with different perspectives and backgrounds. Results of this study could 
also be useful for decision makers of other natural recreational sites of Malaysia as they try to discern visitors' general preferences and the way they trade them off with money.

\section{Penang National Park}

Penang National Park (PNP) is located in the northwest corner of Penang Island, a metropolis in Northern peninsular Malaysia (Figure 1). PNP is the first national park established under Malaysia's National Park Act of 1980, Act No. 226 enacted by the federal and state governments as a measure to protect the rich biodiversity endangered by the nearby metropolis [4]. The park, formerly a forest reserve which until 1996 had been used for logging, is known for its coastal ecosystem of approximately 1266 hectares, of which 70 hectares are still regarded as virgin forest [24,25]. PNP, which has both forest and marine features, had attracted a wide range of visitors. Penang National Park was set up to preserve and protect "flora and fauna, geological, archaeological, historical, ethnological features and other scientific value and scenic interest" [26].

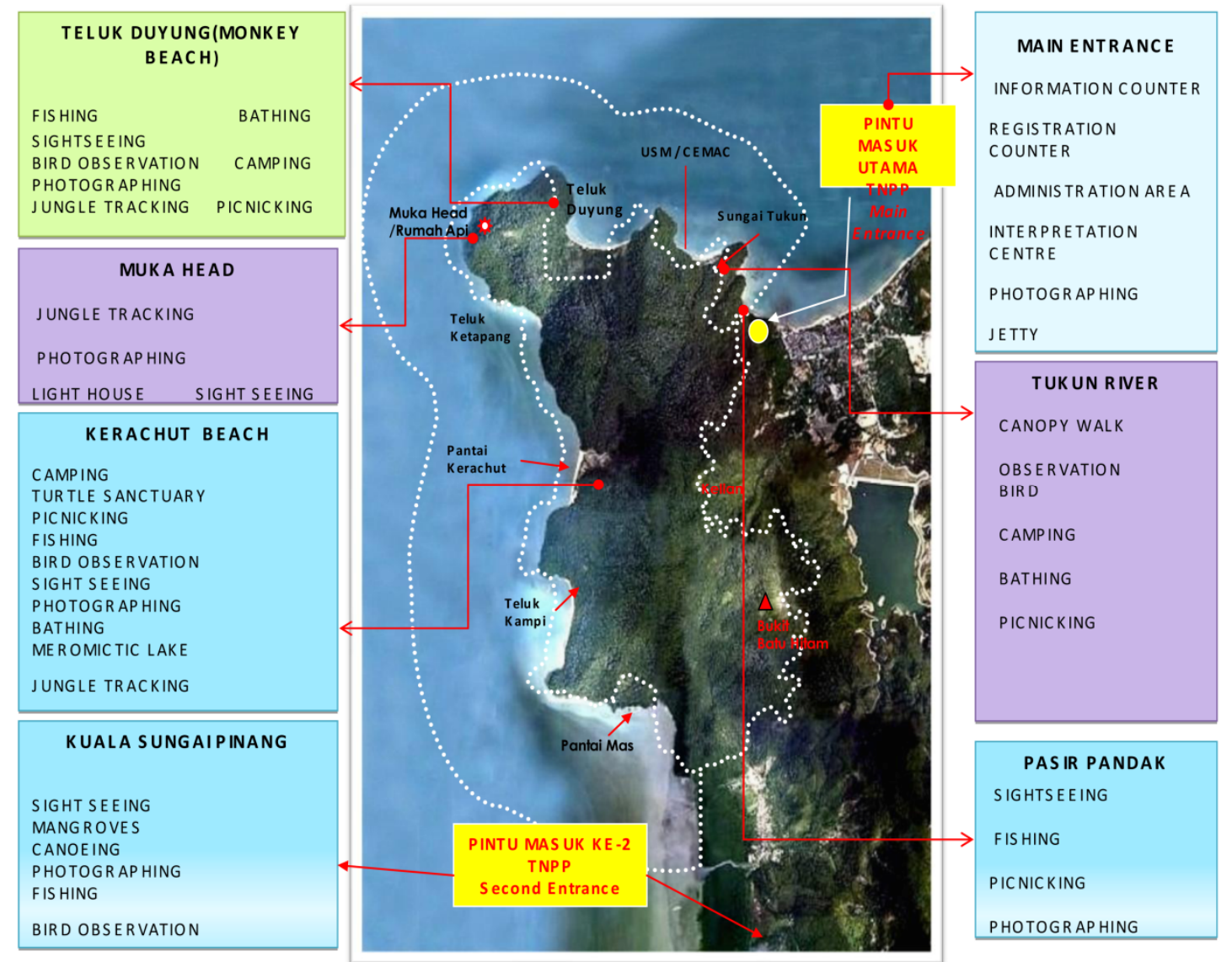

Figure 1. Penang National Park (Locations and Activities) [4]. Source: Modified from http://www.journeymalaysia.com/islandpenangtrekking_map.htm.

PNP is the only national park in Peninsular Malaysia with a coastal habitat which provides diverse range of habitats from sandy and rocky shores to mangroves, for wide range of flora and fauna species [4]. 
Teluk Bahang, Pantai Kerachut, Pantai Mas and Teluk Duyung (Monkey Beach) are the famous four of the eight pristine and sandy beaches around the forest [27]. Over 1000 plant species and one unique species, namely Stag Horn's Fern (Platycerium coronarium), have been reported in PNP [28]. The park is also home to 90 species of medicinal plants. In addition, almost 200 species of birds, 25 species of mammals, 53 species of butterflies, and a sizable diversity of marine species have been recorded from PNP $[25,28]$. The park's inimitable features and habitats such as the meromictic lake and turtle nesting sites are unique to PNP.

Some of the coastal areas in PNP are abodes to mangrove forests. They are found on the northern, western and southern coasts. Kuala Sungai Pinang consists of mangrove areas, making it a good bird-watching site for avid bird watchers. Bird species that can be found there include Little Heron, Haliaeetus Leucogaster (Helang Siput), Haliastur Indus (Lang Merah), and some other small colorful birds, such as sunbirds (Kelicap) and sandpipers (Kedidi).

The first main entrance to PNP is located in Teluk Bahang, and visitors need to register for the entry permit at the National Park's illumination counter. The second entrance is in Balik Pulau, nestled in Kuala Sungai Pinang. From there, visitors must get a visitors' boat to get to PNP. While entrance to PNP is free, tourists need to register by name at the office before entering the park and sign out before leaving. Information signs, mostly near the registration point, point out walking trails, directions, and other useful and interesting information. Penang National Park only receives day visitors. For overnight camping, visitors must receive permission from the Park's management. Due to limited water supplies and possibility of rain, the overnight camper limit is 80 at the Pantai Kerachut campsite and 30 at the Sungai Tukun campsite.

From the main entrance of PNP, three trails diverge, heading to different natural habitats. The park has provisions for varied ecotourism activities: climbing, trekking, swimming, fishing, wildlife observation, or simply enjoying the natural environment of sea and forest scenery. Camping and picnic facilities are provided in Pantai Kerachut (a white sandy beach). This beach also hosts a Green Turtle (Chelonia mydas) nesting ground between April to August, and one for the Olive-Ridley turtle (Lepidochelys olivacea) from September and February [24]. Nevertheless, most visitors do not have enough information about these two species, and there is no guarantee that turtles' habitat will not be disturbed by visitors.

Although visitors are reminded to deposit their litter in the "monkey-proof" trash in monkey beach, discarded, mostly plastic, containers used by visitors are scattered across the beach and along the trails. Hence, environmentalist groups have launched an effective awareness and environmental education system for all stakeholders, involving the development of a sustainable management plan and environmentally-friendly infrastructure, and focusing in PNP on ecotourism rather than mass tourism [25].

The park's relatively aggressive and unbalanced infrastructure development has greatly disrupted its natural tranquility and other ecological harmonies, such as species balance. An example is the construction of roads and strings of camping facilities within and just outside the park. Further, the Wildlife Department is the sole decision-maker in park management; its failure to consult relevant governmental and non-governmental organizations in key decisions, whether deliberate or through negligence, has resulted in noncompliance and a number of government policies which contradict one another. However, ecological threats to PNP are not merely a result of PNP's currently excessive 
attention to mass tourism development and the unsustainably large numbers of tourists who enter the park. Inadequate park management, including lack of proper zoning and failures to protect park borders, has resulted in destruction of critical habitats and of the park's overall ecosystem. This is beyond the encroachment of urban and agricultural land use into the park. Poor enforcement, lack of trained guides, and lack information about sensitive areas or allowed practices in different ecological zones are other important challenges to the park's natural tranquility and sustainable tourism [25].

\section{Methodology}

Valuation methods can be divided into stated and revealed preference techniques. While revealed preference techniques can only capture use values, the stated preference methods are the only way to estimate non-market and non-use values. These methods include contingent valuation method (CVM) and choice experiment (CE) analysis. National parks managers need to consider both protection priorities and visitor satisfaction, so methods must be able to study the multi-dimensionality of parks [7]. However, CVM and CE are similar in their theoretical basis, survey design, and the capability to estimate welfare for moving from a current condition (status quo) to an alternative level. The choice experiment (CE) method can also provide multidimensional information for a certain park and calculation of trade-offs between goods in the choice set or attributes and price helps to highlight any prioritized park attributes. Accordingly, a choice experiment method was used in this study to weigh the complex dimensions of both park preservation and the visitors' experience of enjoyment.

\subsection{Survey Design}

The choice experiment (CE) questionnaire used for data collection highlights problem statements, choice sets, and socioeconomic and attitudinal questions. A clear definition of these sections can assure more reliable responses [29,30].

The first step in designing the questionnaire required determining the most important attributes of management with the aim of saving both ecological integrity and tourism development. The selection of alternative attributes can be done through expert surveys, scientific research, and focus group discussions. Hence, the most policy-relevant attributes which have future practical influence in PNP management were selected. Present short-term practice in PNP is geared towards attracting mass tourism, while we are more concerned about sustainable tourism medium-range and long-term ecological integrity. Current practices involve medium- and long-term risks to the operation. Therefore, the attributes chosen for this study were ecological management (with emphasis on the protection of ecological integrity), recreational facilities (with emphasis on considering park capacities and being as nature friendly as possible), provision of information and price. We defined minimum and maximum attribute levels, where the minimum level reflects the current situation. These selected attributes ensued from a synthesis of opinions based on the outcome of focus group discussions with stakeholders including park managers, tour guides, DWNP experts, and researchers who are familiar with PNP. Nonetheless, the final decision on attributes and levels was also based on our personal observations at the park. The final priorities selected, therefore, were those directly affecting decision making and park management in ways which would optimize tourist comfort with minimal ecological 
impact. In conformity to the study's objective, it was ensured that the selected attributes are those related to recreation, tourism and conservation.

\subsubsection{Attributes and Levels}

The attributes considered for the assessment of visitors' preferences were ecological management, recreational facilities, information boards, and entrance fee. The inclusion of the monetary attribute might help park managers consider the introduction of an entrance fee for PNP, as admission is currently free of charge. Imposing an admission fee creates an entry barrier and could help to reduce congestion by imposing a marketplace decision on spending on potential visitors, who now must sort their preferences for visiting the site with their other possible uses for the money. However, on the positive side, the possibly greater overall revenue it generates could be spent on programs which would enhance public education, guards' training, research, and conservation projects, which could help mitigate environmental problems inside the PNP.

The four attributes used in the final design, as discussed earlier, are listed in Table 1. One of the attributes is treated as a cost, while the other three attributes represent improvement in management of the park, although they also impose costs, which may or may not be charged back to visitors as fees.

Table 1. Attributes and Levels Selected for PNP.

\begin{tabular}{clc}
\hline \multicolumn{1}{c}{ Attribute } & Attribute Levels & $\begin{array}{c}\text { Current Management } \\
\text { Practices }\end{array}$ \\
\hline \multirow{3}{*}{ Ecological management (EV) } & $\begin{array}{l}\text { 1. Current condition } \\
\text { 2. Satisfied }\end{array}$ & Not satisfied \\
& 3. Very good & \\
1. Current condition & Not satisfied \\
Recreational facilities (RF) & 2. Satisfied & \\
& 3. Very satisfied & Low \\
1. Current condition & \\
Provision of information (PIS) & 2. Medium & \\
& 3. High & RM 0 \\
& 1. Current condition & \\
2. RM 5 & \\
& 3. RM 10 10 & \\
4. RM 15 &
\end{tabular}

- Ecological Management: The term "ecological management" refers to the proper management of the park with minimum negative effect on flora, fauna, and the quality of the physical environment, such as water purity and natural scenery. From our focus group discussion with stakeholders, we learned that waste disposal, urban encroachment into the park, lack of zoning, and poor infrastructure were major threats to the ecosystem. Thus, the effects of encroachment, improper waste disposal and declining numbers of animal and plant species, either due to visitor or management disturbance, were highlighted and presented to the respondents. The three levels considered for this attribute include:

1. Current condition (not satisfied): This reflects the status quo, where encroachments are ignored, waste disposal is uncontrolled, zoning of the park is not clear, and infrastructure construction is not environmentally friendly enough. This status quo level leads to natural environment disturbance. 
2. Satisfied: This denotes a relatively more desirable level where encroachments are addressed and controlled, and waste disposal is controlled through the provision of enough trash collection bins along the trails and the coast. In addition, the park management distinguishes restricted areas for tourism, while infrastructure construction inside the park is minimized.

3. Very good: This implies the best conditions with prevention of encroachment, a clean environment and scheduled waste management, provision of enough trash collection bins along the trails and coast, and the provision of education and enforcement programs through park guides. These measures are implemented in addition to park zoning, allowing visitors patronage only to recreational and economic activity zones. Moreover, strict access controls are enforced in and around construction projects, even in areas adjacent to the park.

- Recreational Facilities: This study contemplated the facilities' quality and numbers of washrooms; availability of showers, shelter, and picnic areas; safety nets or guard rails; and the cleanliness of beach areas. The levels of this attribute include:

1. Current condition (Unsatisfactory): This denotes the status quo, where only limited numbers of washrooms and showers are available at the entrance: Sungai Tukun and turtle beach. Guard rails and safety nets are rare, and waste has been allowed to litter surroundings, most visibly along the beach.

2. Satisfactory: This envisions relatively better facilities including the provision of washroom and camping facilities for 150 campers at a time in allowed zones, providing safety ropes in dangerous area especially for children and elderly people. This is besides keeping the beach areas fairly clean.

3. Very satisfactory: This level describes the best provision of facilities including washrooms, water supply, and camping areas for 200 campers at a time, providing safety ropes wherever needed along trails, and keeping beach areas very clean.

- Provision of Information: This includes the provision of information about flora, fauna, and park attractiveness. This could be useful to educate visitors and communities living near the ecotourism sites. This enhanced and relevant awareness might later encourage the nearby residents to support nature protection in the nearby park and to reduce the degradation of the park's resources. Providing information can be achieved through availability of interpretive programs, deftly positioning information boards, signboards, and posters in the right places, where relevant brochures and pamphlets are also made available. The effectiveness of this program depends on how well the park's visitors can get useful information inside the park. This means the design of the materials and their distribution and availability at appropriates place will determine how effectively even well-designed, well-written information can be used. Inside PNP at present, the tour guides are neither licensed nor trained; training them would be very helpful in providing information for tourists.

1. Current condition (Low): This denotes limited information, direction, and signs only for management and safety purposes; informative paper factsheets, brochures, and pamphlets are only available at the information counter; guides are not educated about the park's mission, features, history, and ecological utility. 
2. Medium: This describes a better condition, where directions and signs for management and user safety are provided in key intersections. Signs are easy to read and identifiable, park guards and educated guides provide information on turtle beach and for some critical habitats and species of the park.

3. High: This proposes the best level of providing information services, where directions and signs for management and safety are provided in intersections and near camping area and restrooms, and where park guards and guides act as one-on-one guides to visitors in the park, enlightening them on how to contribute to the sustainability of the park and environmental friendly use of the park.

- Cost: Although entrance to the PNP is free at this time, PNP managers are being asked to reflect on the acceptability of introducing an entrance fee. The payment vehicle attribute must be defined carefully so that all the respondents are able to act as they make the real choices and, therefore, any hypothetical bias in the study can be reduced $[3,15]$. Suggestions for the entrance fee include possible payments of RM 0, RM 5, RM 10, and RM 15.

\subsubsection{Choice Sets Design}

Applying the full factorial design from an original set of attributes and levels allowed 108 $(3 \times 3 \times 3 \times 4)$ possible combinations. Implementing the full factorial design is difficult because it contains so many combinations. Hence, we applied an orthogonal main effect design (using SPSS) to generate a smaller number of combinations. The final design included 8 alternatives in four choice sets, each choice set including two proposed alternatives plus the status quo. Alternatives A and B entailed various combinations of suggested management policy-attributes, along with cost, while alternative $\mathrm{C}$ always represented the current situation, at no additional monetary cost. The choice of alternative $\mathrm{A}, \mathrm{B}$, or $\mathrm{C}$ to each question yielded information about the selected scenario for a given respondent (Table 2).

Table 2. Sample of choice sets.

\begin{tabular}{|c|c|c|c|}
\hline ATTRIBUTE & MANAGEMENT OPTION A & MANAGEMENT OPTION B & $\begin{array}{c}\text { CURRENT MANAGEMENT } \\
\text { PRACTICE }\end{array}$ \\
\hline $\begin{array}{l}\text { Ecological management } \\
\text { Proper management of the park } \\
\text { with minimum negative effect on } \\
\text { flora, fauna and physical } \\
\text { environment quality such as water } \\
\text { quality and natural scenery }\end{array}$ & $\begin{array}{c}\text { Very Good } \\
\text { Enough trash bins everywhere, } \\
\text { provision of information by } \\
\text { educated guards, tourism activity } \\
\text { only in recreational and economic } \\
\text { zone, no construction is allowed }\end{array}$ & $\begin{array}{c}\text { Very Good } \\
\text { Enough trash bins everywhere, } \\
\text { provision of information by } \\
\text { educated guards, tourism } \\
\text { activity only in recreational and } \\
\text { economic zone, no construction } \\
\text { is allowed }\end{array}$ & $\begin{array}{c}\text { Not Satisfied } \\
\text { Uncontrolled waste disposal, no } \\
\text { zoning, environmental disturbance }\end{array}$ \\
\hline Recreational facilities & Very Satisfied & Satisfied & Not Satisfied \\
\hline $\begin{array}{l}\text { Quality and numbers of } \\
\text { washrooms, availability of shower } \\
\text { room, shelter and picnic areas, } \\
\text { availability of interpretive } \\
\text { programs, safety nets or guard } \\
\text { rails and cleanliness of beach areas }\end{array}$ & $\begin{array}{l}\text { Provision of facilities including } \\
\text { washroom, water supply and } \\
\text { camping area for } 200 \text { campers at } \\
\text { one time, providing safety ropes } \\
\text { wherever needed along trails, } \\
\text { very clean beach areas }\end{array}$ & $\begin{array}{c}\text { Provision of enough } \\
\text { washrooms and facilities for } \\
150 \text { campers at one time, } \\
\text { providing safety ropes in } \\
\text { needed area considering kids } \\
\text { and elderly people, fairly clean } \\
\text { beach area }\end{array}$ & $\begin{array}{l}\text { Limited numbers of washrooms and } \\
\text { showers, Guard rails and safety nets } \\
\text { are rare and waste is allowed to } \\
\text { litter surroundings most especially } \\
\text { along the beach }\end{array}$ \\
\hline
\end{tabular}


Table 2. Cont.

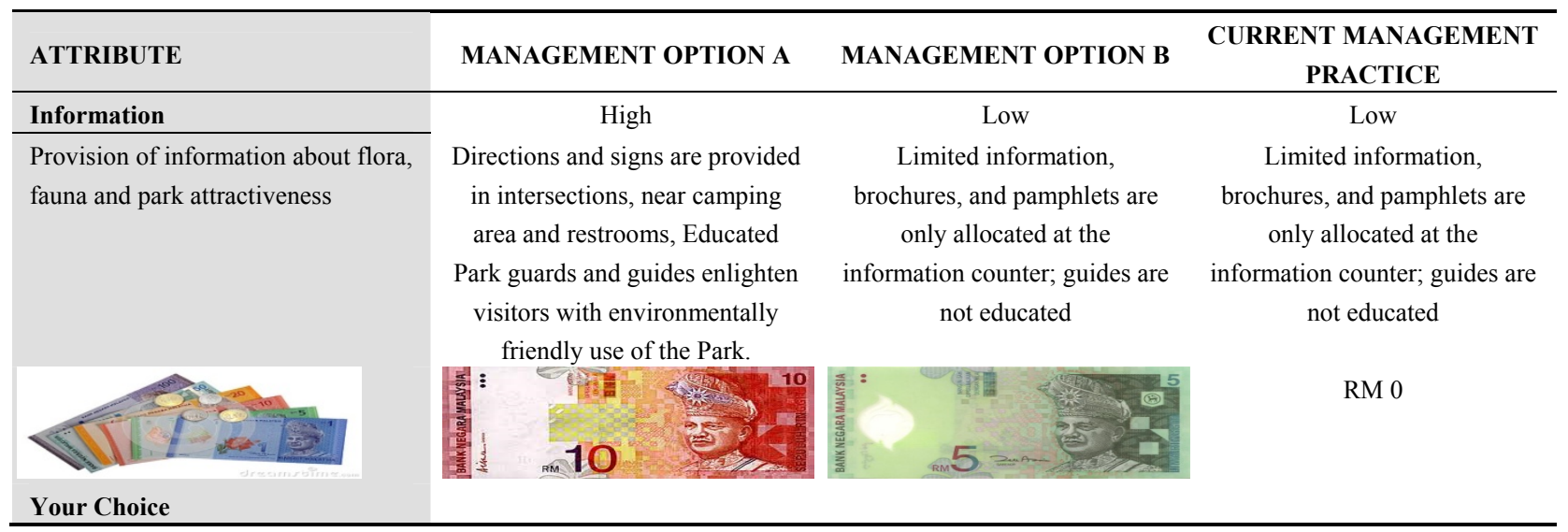

While the sets of alternatives change between questions, an analysis of numerous responses allows a statistical estimation of each attribute level's perceived value. It is assumed that responses from a given respondent are independent [31]. As such, in regression analysis, the total number of valid responses to the choice questions indicates the sample size and not the number of sampled respondents [31]. Once the set of attributes and levels were defined and choice sets were developed, the questionnaire was prepared in Bahasa Malay and English versions, to present to the surveyed tourists.

\subsection{Sampling and Data Collection}

Using outcomes from an initial pilot study on visitors at the park, the final version of the questionnaire was prepared, consisting of four parts. The first part was introductory script and information about PNP, highlighting the values of the park and the problems it is facing. This part was followed by information on PNP choice sets and definitions on attributes of the choice experiment and related levels such as ecological management, tourist guides, recreational facilities, provision of information, and entrance fees. Follow-up questions were included to capture the respondents' reason for selecting current condition or "status quo." "The questions are ambiguous", or "I do not accept paying an entrance fee to enter the national parks" or "I agree with current management policies, and it should continue operating with only tax revenues, as in past years" were some of the options presented to the respondents.

The second part contained questions to gauge visitors' attitudes towards the park. This part included questions related to respondents' information about the park, their reasons for interest in visiting this park, and their number of previous visits to this park. The third part contained some questions to elicit the respondents' preferences on "improvement in management strategies", "ecotourism development", and their views on "implementing an entrance fee for PNP" with a five-point (Likert-like) scale: extremely important, important, of average importance, of little importance, or not important at all. The final section included questions to obtain the socioeconomic status of the respondents. This section included questions about their age, gender, occupation, education level, income level, residential status, and nationality.

The survey was conducted at PNP from February through April 2012. Based on the National Oceanic and Atmospheric Administration (NOAA) panel guidelines [32], in-person interviews with 
park visitors were considered appropriate. The target population included both domestic and foreign visitors. A systematic random sampling method was used for sampling purpose. It means every nth visitor aged over 18 years old was intercepted when passing by the interviewer, then asked about their interest and time to fill out the survey. The study location was chosen to ensure that the tourists had visited the PNP and that they were walking toward an exit from the park. This approach was taken because the experience of the respondents from the park and its existing conditions could help them to respond more accurately. The surveys were carried out simultaneously at specified locations (the park's two main exits are Monkey Beach and the main gate). This chosen method was considered fair and representative, as it ensures that all populations would have an equal chance to be selected as respondents. The data collection was carried out continuously from 9:00 am to 6.00 pm. The Mitchell and Carson CV method was applied to estimate the sample size [33]. Mitchell and Carson suggested considering a coefficient of variation of 2.0 when determining sample size [33]. Therefore, using their formula and tolerating the disparity of $20 \%$ between the true population mean and sample estimate, the mean sample size of 286 was estimated [33]. Considering this and our available budget, a sample size of 300 respondents was determined for this study. Overall, 12 responses were eliminated on account of either continuous selection of status quo-without considering it as their best choice - or incomplete answers to choice questions. Therefore, their answers were considered a mimic of protest vote and thus were eliminated from the analysis. However, those respondents with genuine zero-bid were retained. These are those respondents who "However, agreed with improvements but could not afford to pay" and "preferred to spend that money on other things". Statistical analysis and model estimation was carried out using SPSS (Ver.17) and Nlogit 5 software.

\subsection{Econometric Models}

A random parameter logit model (RPL) which is a generalization of the standard multinomial logit model (MNL) is applied in this study for two main reasons. First, it explicitly accounts for unobserved preference heterogeneity across respondents; and second, it assumes that the alternatives are not independent [34]. Thus, it has an advantage of relaxing the assumption of Independence of Irrelevant Alternatives (IIA) [35].

The RPL relies on random utility theory [36,37] and the economic theory of value [38] to provide a utility theoretic interpretation of the discrete responses derived from respondents. The individual utility function (U) for each respondent (i) could be disaggregated into two parts. One such part is the deterministic component (V), which would typically be specified as a linear index of the attributes (X) of the $j$ th alternative in the choice set. The second component is a stochastic element $(\varepsilon)$ which represents the error term:

$$
U_{i j}=V_{i j}\left(X_{i j}\right)+\varepsilon_{i j}=\beta_{i} X_{i j}+\varepsilon_{i j}=\beta^{\prime} X_{j}+b X_{j}+\varepsilon_{i j}
$$

where $\mathrm{U}_{i j}$ is the utility individual $i$ obtains from alternative choice set $j, \mathrm{~V}_{i j}$ is a non-stochastic (determinist) utility function, $\varepsilon_{i j}$ is a random component. In the right side of the model the decomposition of utility functions, $\beta$ refers to sum of population mean $\left(\beta^{\prime}\right)$ and individual deviation from the mean (b). 
For instance, consider a case where an individual $(i)$ is asked to choose between alternative goods $\left(\mathrm{V}_{j}\right.$ and $\mathrm{V}_{k}$ ) that are assumed to be differentiated by their attributes and levels. In choosing between them, the respondent is assumed to compare the utility that he or she could get with either choice before selecting the alternative or the higher utility:

$$
P_{i j}=\left(V_{i j}+\varepsilon_{i j}\right)>\left(V_{i k}+\varepsilon_{i k}\right)=P\left[\left(V_{i j}-V_{i k}\right)>\left(\varepsilon_{i j}-\varepsilon_{i k}\right)\right]
$$

Each attribute, except for the cost in terms of monetary value (CC), was divided into three levels. The status quo, or Level 1, was set as the baseline, and Levels 2 and 3 were agreed to imply proposed management options, respectively. Attribute levels were "dummy coded," meaning they were set equal to 1 if the corresponding level was present, and set to 0 otherwise. In all models, the base level was the status quo.

For an estimation of willingness to pay (WTP), the following formula can be applied:

$$
M R S=\beta \times 1 / \beta C
$$

This value for any attributes (other than price) is called implicit price or marginal rate of substitution (MRS). For marginal change in an attribute, WTP value is typically derived by dividing the $\beta$ value of each non-monetary attribute by the $\beta$ value of the price attribute. The specification of RPL can be found in Hensher and Greene [34] and Hensher et al. [39,40].

\subsection{Structural Equation Modelling}

\subsubsection{Exploratory Factor Analysis}

Factor analysis has been widely used in social science literature to identify and categorize the latent structure of a set of variables. Therefore, a large set of variables which measure similar things will get into a smaller set of unobserved variables called factors. In the present study, 18 attitudinal items were collected from respondents. These variables were measured on a five-point (Likert) scale ranging from 1 (not important at all) to 5 (extremely important). Nevertheless, including all 18 items in the WTP model seems rather impractical. Hence, in the present study, exploratory factor analysis was applied in order to reduce 18 attitudinal items into a smaller number of identified factors [41]. In order to examine the appropriateness of items to use in factor analysis, the reliability test using Cronbach's alpha was conducted. Reliability of factors in this research was guaranteed with Cronbach's alpha value higher than 0.7 threshold [42]. Using a reliability test, one item was eliminated. Conducting correlation estimation between variables showed that multicollinearity is not an issue. To measure the validity of the latent variables, exploratory factor analysis with Promax rotation was applied in SPSS software.

\subsubsection{Confirmatory Factor Analysis}

Structural equation modelling (SEM) was employed in order to analyse factors influencing each person's choice using observed and latent variables (Confirmatory Factor Analysis). SEM as a statistical tool can be used to analyse and estimate the casual relationships between different observed and latent variables. Latent variables (or hidden variables) are those variables which are not observed directly but which are inferred from other observed variables. It is worth noting that SEM can take 
both direct and indirect relationships. This means that some relation between variables might be improved by interconnecting them. SEM results can be decomposed to the measurement model and the structural model [43]. While the measurement model defines the relationships between latent variables and their observed indicators, the structural model explains the relationships between and among exogenous and latent endogenous variables. Endogenous variables are those that are dependent at least in one of the models equations. In the present study, as suggested by Hess and Beharry-Borg [44], it was assumed that answers to attitudinal questions are only a function of underlying attitudes rather than a direct measure of them. In contrast, exogenous or independent variables are observed variables, such as the socio-demographic information of respondents.

If we assume $y=\left(y_{1}, y_{2}, y_{3}, \ldots y_{\mathrm{p}}\right)$ is vector of observable endogenous variables and $x=\left(x_{1}, x_{2}, x_{3}, \ldots, x_{q}\right)$ is vector of observable exogenous variables, the measurement model can be written as follow [43]:

$$
\begin{aligned}
& y=\Lambda_{y} \eta+\varepsilon \\
& x=\Lambda_{x} \zeta+\delta
\end{aligned}
$$

where $\Lambda_{\mathrm{y}}$ and $\Lambda_{\mathrm{x}}$ are $(\mathrm{p} \times \mathrm{m})$ and $(\mathrm{q} \times \mathrm{n})$ matrices of regression coefficients. The $y$ variables are function of some latent endogenous variables so called $\eta$ 's, while $x$ variables are vector of latent exogenous variables so called $\zeta$ 's.

The structural equation model which specifies the relations between these latent variables can be expressed as follows [43]:

$$
\eta=\mathrm{B} \eta+\Gamma \zeta+\zeta
$$

where $B$ is an $(\mathrm{m} \times \mathrm{m})$ coefficient matrix with the regression coefficient measuring the effect of the $\eta$ 's endogenous variable on the other $\eta$ 's endogenous variables; $\Gamma$ is a $(m \times n)$ coefficient matrix representing the effect of the $\zeta$ 's exogenous on the $\eta$ 's endogenous variables; $\zeta$ is the vector of the error term.

The conceptual model based on equations (4-6) reads as:

$$
\begin{aligned}
& y=\left(\begin{array}{c}
y_{1} \\
y_{2} \\
y_{3} \\
\cdot \\
\cdot \\
\cdot \\
y_{17}
\end{array}\right)=\left(\begin{array}{ccccc}
1 & 0 & 0 & \ldots & 0 \\
\gamma_{2,1} & 0 & 0 & \ldots & 0 \\
\gamma_{3,1} & 0 & 0 & \ldots & 0 \\
& & \cdot & & \\
& & \cdot & & \\
0 & 0 & 0 & . & \\
\eta_{17, n}
\end{array}\right)\left(\begin{array}{c}
\eta_{1} \\
\eta_{2} \\
\eta_{3} \\
\cdot \\
\cdot \\
\cdot \\
\eta_{n}
\end{array}\right)+\left(\begin{array}{c}
\varepsilon_{1} \\
\varepsilon_{2} \\
\varepsilon_{3} \\
\cdot \\
\cdot \\
\cdot \\
\varepsilon_{17}
\end{array}\right) \\
& \mathrm{x}=\left(\begin{array}{c}
\text { Age } \\
\text { Gender } \\
\text { Education } \\
\cdot \\
\cdot \\
\cdot \\
\mathrm{x}_{8}
\end{array}\right)=\left(\begin{array}{ccccc}
1 & 0 & 0 & \ldots & 0 \\
0 & 1 & 0 & \ldots & 0 \\
0 & 0 & 1 & \ldots & 0 \\
& \cdot & \\
& & \cdot & \\
& \cdot & \\
0 & 0 & 0 & \ldots & \\
&
\end{array}\right)\left(\begin{array}{c}
\text { Age } \\
\text { Gender } \\
\text { Education } \\
\cdot \\
\cdot \\
\cdot \\
\mathrm{x}_{8}
\end{array}\right)
\end{aligned}
$$

The structural model as then can be expressed as: 


$$
\left(\begin{array}{c}
\eta_{1} \\
\eta_{2} \\
\eta_{3} \\
\cdot \\
\cdot \\
\cdot \\
\eta_{n}
\end{array}\right)=\left(\begin{array}{ccccc}
0 & \beta_{1,2} & \beta_{1,3} & \ldots & \beta_{1, n} \\
\beta_{2,1} & 0 & \beta_{2,3} & \ldots & \beta_{2, n} \\
\beta_{3,1} & \beta_{3,2} & 0 & \ldots & \beta_{3, n} \\
& & \cdot & & \\
\beta_{n, 1} & \beta_{n, 2} & \ldots & \beta_{n, n-1}, 0
\end{array}\right)\left(\begin{array}{c}
\zeta_{1} \\
\zeta_{2} \\
\zeta_{3} \\
\cdot \\
\cdot \\
\zeta_{n}
\end{array}\right)
$$

It is important to note that in the measurement model for identification purposes, one of the coefficients of each latent variable set as 1 . In structural model, however, absence of impact between variables results in setting that coefficient at zero.

\section{Statistical Results}

\subsection{Sample Characteristics}

The characteristics of respondents are shown in Table 3. Large percentages of visitors at the PNP were locals $(84.7 \%$ vs. $15.3 \%)$. The respondents were between 18 to 76 years old and majority of them were men $(64 \%$ vs. $36 \%)$. The number of married respondents $(58 \%)$ was slightly larger than unmarried ones $(42 \%)$. In terms of occupation, a majority of the respondents were working in the private sector (59\%), $28 \%$ in governmental organizations, $4.8 \%$ were students, and $7.6 \%$ were retired. About $34 \%$ of the respondents were from a rural area, and the rest (60\%) from an urban area. In terms of education, $30 \%$ had a university degree, and the rest had some college education (13\%), secondary school (54\%), or only primary school (3\%). The average income of visitors was RM 3600 per month. With respect to the local demographics, the Malaysian household average monthly income is MYR4025 per month, while about $60 \%$ of households earned around MYR3500 or less [45]. The income levels as gauged by this study were therefore representative of the Malaysian people broadly.

Table 3. Socio demographic characteristics of the respondents.

\begin{tabular}{cccccc}
\hline \multirow{2}{*}{ Variable } & \multicolumn{2}{c}{ Frequency } & \multirow{2}{*}{ Mean } & St. Deviation & \multirow{2}{*}{ Type of Varible } \\
\cline { 2 - 4 } Gumber & $\mathbf{( \% )}$ & & 0.64 & 0.48 & dummy \\
Male & 159 & 63.9 & & & \\
Female & 90 & 36.1 & & & \\
Age & & & 36 & 0.13 .03 & continues \\
Citizenship & & & & & \\
Malaysian & 211 & 84.7 & & & \\
Other & 38 & 15.3 & & & \\
Strata & & & & & \\
Urban & 163 & 65.5 & & & \\
Rural & 86 & 34.5 & & & \\
Education Level & & & 14.77 & & \\
Primary school & 7 & 2.8 & & & \\
Secondary school & 135 & 54.2 & & & \\
College & 33 & 13.3 & & & \\
University & 74 & 29.7 & & & \\
Marital Status & & & 0.58 & & \\
Single & 105 & 42.2 & & & \\
Married & 114 & 57.8 & & & \\
\hline
\end{tabular}


Table 3. Cont.

\begin{tabular}{cccccc}
\hline \multirow{2}{*}{ Variable } & \multicolumn{2}{c}{ Frequency } & Mean & St. Deviation & \multirow{2}{*}{ Type of Varible } \\
\cline { 2 - 3 } Employment & Number & $\mathbf{( \% )}$ & 2.23 & 1.14 & categorical \\
$\quad$ Student & 12 & 4.8 & & & \\
Government Sector & 72 & 28.9 & & & \\
Private sector & 146 & 58.7 & & & \\
$\quad$ Retired & 19 & 7.6 & & & \\
Income (MYR) & & & 3649.2 & 6323.8 & \\
Sample size & 288 & & & & \\
\hline
\end{tabular}

\subsection{Results of Exploratory and Confirmatory Factor Analysis}

As Table 4 shows, the results of exploratory factor analysis revealed three interpretable factors with Eigen values greater than 1 . The first latent variable was formed from 6 attitudinal variables related to respondents' concern on PNP's importance as a national park (NP). The second latent construct was established from four attitudinal variables related to PNP management concerns (MNG). The third latent variable was constructed from three attitudinal variables related to an ecotourism perspective on PNP (TOUR).

Table 4. Factor Structure of Visitor's Perceptions on PNP

\begin{tabular}{|c|c|c|c|c|}
\hline \multirow{2}{*}{ Variables } & \multicolumn{3}{|c|}{ Factors } & \multirow{2}{*}{$\begin{array}{l}\text { Cronbach's } \\
\text { alpha }=\mathbf{0 . 7 9 7}\end{array}$} \\
\hline & NP & MNG & TOUR & \\
\hline Visiting Penang National Park has encouraged me towards conservation efforts & 0.530 & & & 0.787 \\
\hline Activities in PNP promote Environmental Education programs & 0.608 & & & 0.781 \\
\hline PNP provides an important view point on interaction between human and nature & 0.551 & & & 0.785 \\
\hline $\begin{array}{l}\text { Conservation efforts at PNP have increased my awareness of the importance of } \\
\text { national parks }\end{array}$ & 0.434 & & & 0.784 \\
\hline PNP has an important role in provision of environmental information & 0.678 & & & 0.789 \\
\hline PNP has an important role as ecotourism destination & 0.710 & & & 0.778 \\
\hline $\begin{array}{l}\text { Interactive programs like fishing and canopy walking and camping increased } \\
\text { my knowledge about the value of protected areas }\end{array}$ & 0.688 & & & 0.779 \\
\hline PNP has a role in wildlife conservation & 0.732 & & & 0.780 \\
\hline PNP is of great value for conducting research & 0.619 & & & 0.779 \\
\hline Provision of a better integrated management plan in PNP & & 0.569 & & 0.781 \\
\hline Better enforcement of rules and regulation & & 0.752 & & 0.788 \\
\hline Implementing entrance fees for conservation charge & & 0.728 & & 0.784 \\
\hline $\begin{array}{l}\text { PNP authorities and managers find additional sources of revenue for efficient } \\
\text { management purposes }\end{array}$ & & 0.615 & & 0.785 \\
\hline $\begin{array}{l}\text { Implement licenses or permits and charges, on certain activities such as fishing, } \\
\text { using cameras and camping }\end{array}$ & & 0.462 & & 0.786 \\
\hline Develop and implement the interpretation programme & & & 0.612 & 0.787 \\
\hline Providing licensed guides & & & 0.665 & 0.783 \\
\hline Improvement of recreational facilities & & & 0.546 & 0.787 \\
\hline Implementing tax on tour operators or tourist guide & & & & 0.868 \\
\hline Eigenvalue & 5.63 & 1.93 & 1.18 & \\
\hline
\end{tabular}

Extraction Method: Maximum Likelihood. Rotation Method: Promax with Kaiser Normalization. 
The results of SEM with underlying path diagrams for estimated models are presented in Figure 2, where observed components are shown in rectangles and unobserved (latent) variables in ellipses. In order to reach or determine the best model fit, several models were computed in AMOS. The final model resulted in eliminating highly insignificant variables and consisting of a covariance path to link error terms of latent or observed constructs. Hence, the final result was achieved with 13 variables out of the primary 18. The final model shows all factors' loading are highly significant, with coefficients considerably higher than minimum recommended 0.2 [46]. The standardized total effect on PNP, MNG, and TOUR corresponding to each variable in the model was estimated as well. Results show that interaction with nature and awareness role of PNP have the largest effect on NP with total effect of 0.71 and 0.70 , respectively. Implementing enforcements with rules and regulations and permits and charges on some activities are the two most influential variables of MNG with total effects of 0.75 and 0.73 , respectively. Finally, providing licensed guides, with total effect of 0.73 , and improving recreational facilities, with total effect of 0.58 , are the variables with the largest effect on TOUR. From exogenous variables, only education was found to have a direct and positive effect on latent endogenous variables.

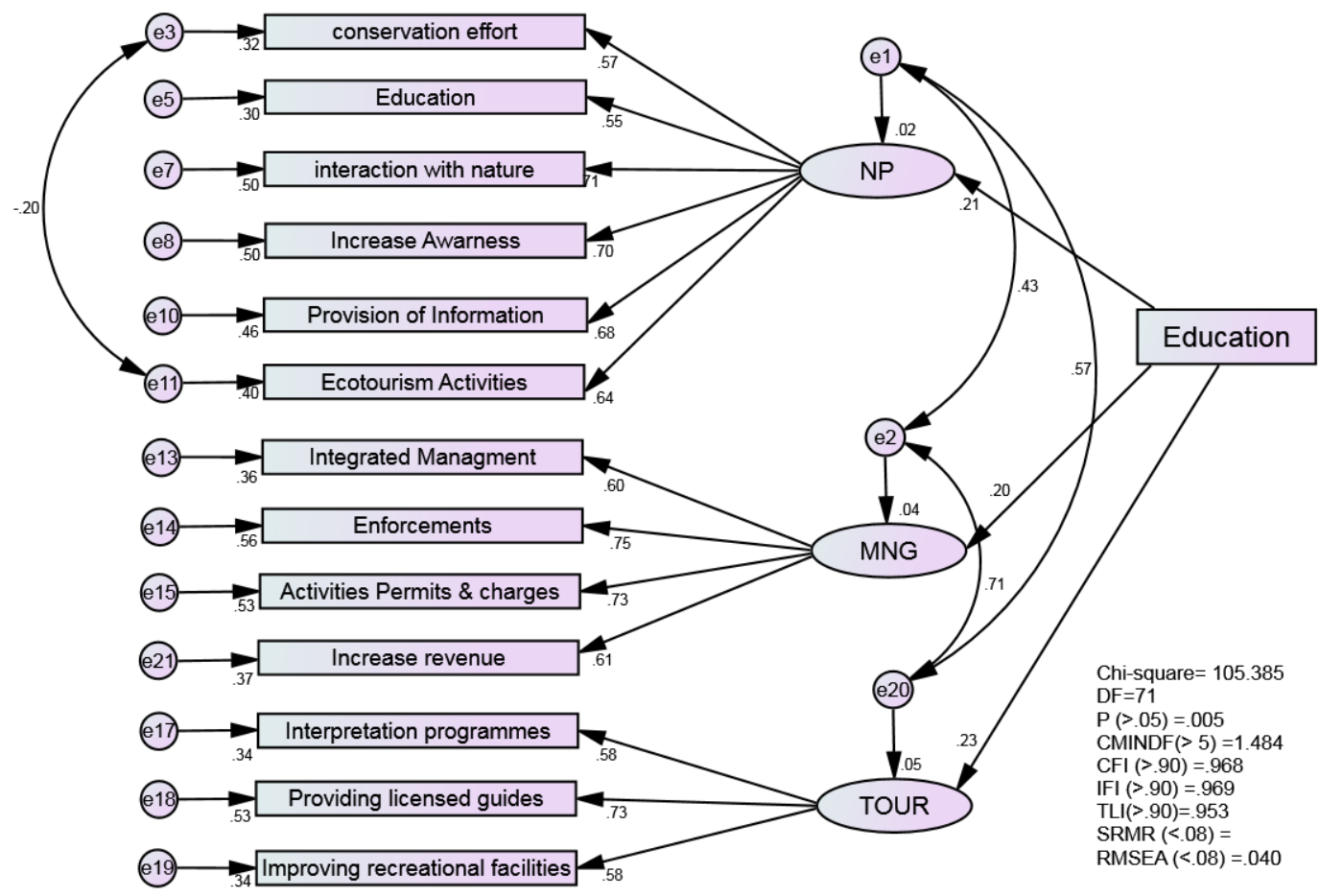

Figure 2. Results of confirmatory factor analysis. All path coefficients shown are completely standardized.

The estimated model has an adequate fit according to the measures of absolute, incremental, and parsimonious fit. The final model shows a normed chi-square value of 1.48 (within the recommended interval of 1 to 3), root mean square error of approximation (RMSEA) values of 0.04 is below the threshold maximum value of 0.08. Comparative fit index (CFI) value and incremental fit index (IFI) value of 0.96 also indicate that the model has a good fit [47]. 


\subsection{Results of Choice Experiment}

In the simple multinomial logit model (MLM) (Table 5), all variables except ecological management (level 2), recreational facilities (levels 2), and cost were significant and exhibited the expected positive sign. This evidences that improvement in ecological management along with recreational facilities and information about PNP is supported by visitors.

Table 5. Results of Simple MNL and RPL Models.

\begin{tabular}{cccccc}
\hline & Multinomial Logit $^{\mathbf{1}}$ & & & \multicolumn{2}{c}{ Random Parameter Logit Model $^{\mathbf{2}}$} \\
\cline { 1 - 3 } \cline { 1 - 2 } Variable & Coefficient & S.E & & Coefficient & S.E \\
\hline EM2 & 1.12 & 1.06 & & 0.07 & 0.40 \\
EM3 & $3.36 * * *$ & 0.65 & & $2.09 * * *$ & 0.49 \\
RF2 & 0.12 & 0.15 & & 0.12 & 0.30 \\
RF3 & $2.50 * *$ & 1.15 & & $1.07 * * *$ & 0.36 \\
PIS2 & $9.26 * * *$ & 3.24 & & $5.77 * * *$ & 2.02 \\
PIS3 & $4.87 * * *$ & 1.15 & & $3.00 * * *$ & 0.49 \\
CC & -0.10 & 0.11 & & $-0.39 * * *$ & 0.11 \\
\hline
\end{tabular}

Notes: $* * *, * *, *==>$ Significance at $1 \%, 5 \%, 10 \%$ level; ${ }^{1} \cdot \log$ likelihood function $=-532.71$, Number of observations $=996 ;{ }^{2} \cdot \log$ likelihood function $=-524.23$, Chi squared $=1167.96$, Significance level $=0.00000$, McFadden Pseudo $R^{2}=0.52$, Number of observations $=996$.

Since the use of an RPL model has advantage of counting for heterogeneity in preferences and paves the way for relaxation of the IIA assumption, we tried to apply an RPL model. Several approaches can be employed to improve model fit and to increase the estimating models' accuracy. Each attribute, except for the conservation value in terms of monetary value $(\mathrm{CV})$, was divided into three levels and recoded as dummy $(0,1)$ : The status quo was set as the baseline, and Levels 2 and 3 were agreed to imply medium and high levels of each attribute, respectively. In all models, the base level was the status quo, or first level of each attribute. Results of simple RPL model are shown in Table 5. Using the likelihood ratio test the estimated value of 16.96 with 6 degrees of freedom was higher than critical value of 16.812 at the $1 \%$ significance level. This implies that the RPL model fits data significantly better than the MNL model. However, the RPL model fit data better than the MNL but neither parameters of EM2 nor RF2 were significant.

In view of the fact that socio-demographic variables remain the same for any given respondent regardless of selecting any given alternative, these variables enter the model through interactions with the attribute variables. The interaction variables comprised 8 socio-demographic and three attitudinal factors interacting with each levels of main attribute. These variables included age, gender, education level, employment situation, income, region, marital status, and visitor's origin. Age, education, and income are continuous variables; others are 1-0 dummies. Only significant variables were retained and reported in the final model. The interaction model is shown in Table 6. The results demonstrated that the pooled RPL model was superior to the simple RPL due to the model fit and expected variables signs. Both simple and extended RPL models were estimated assuming bounded normal distribution [34] based on 150 Halton draws under panel data assumption. We assumed that all variables other than conservation value or cost variable (CC) are random. The cost coefficient was kept fixed to avoid random variations in the cost coefficient. A variable was treated as random if its coefficient of standard deviation was statistically significant at the 10\% level. Results presented in Table 6 are from the final 
model where the variables EM2, EM3, RF2, RF3, PIS2, and PIS3 were found significant and comprising expected signs.

Table 6. Results of pooled RPL Model and IP.

\begin{tabular}{|c|c|c|c|c|}
\hline Variable & Coefficient & S.E & Coeff. std. & Marginal WTP (MYR) \\
\hline \multicolumn{5}{|c|}{ Random parameters } \\
\hline EM2 & $1.82 * * *$ & 0.52 & $1.82 * * *$ & $5.22 *(-0.11$ to 10.55$)$ \\
\hline EM3 & $2.17 * * *$ & 0.62 & $2.10 * * *$ & $6.23 * *(1.07$ to 11.39$)$ \\
\hline RF2 & $0.84 * *$ & 0.42 & $0.84 * *$ & $2.42 * *(0.0078$ to 4.84$)$ \\
\hline RF3 & $2.10 * * *$ & 0.56 & $2.17 * * *$ & $6.03 * * *(1.90$ to 10.16$)$ \\
\hline PI2 & $1.11 * *$ & 0.45 & $1.11 * *$ & $3.17 *(-0.029$ to 6.65$)$ \\
\hline PI3 & $2.97 * * *$ & 0.65 & $2.97 * * *$ & $8.51 * * *(2.16$ to 14.86$)$ \\
\hline \multicolumn{5}{|c|}{ Non-random parameters } \\
\hline $\mathrm{CC}$ & $-0.34 * *$ & -0.13 & & \\
\hline RF3_JOB & $0.31 *$ & 0.18 & & \\
\hline RF3_INC & $0.89 * * *$ & 0.14 & & \\
\hline PIS2_EDU & $0.67 * * *$ & 2.91 & & \\
\hline EM3_EDU & $0.79 * * *$ & 0.26 & & \\
\hline EM3_MNG & $1.96 * * *$ & 0.52 & & \\
\hline
\end{tabular}

The significant standard deviation of all random variables indicates variation of these parameters in the population. This confirms our earlier assumption on presence of preference heterogeneity in the sample.

Since visitors' WTP may be influenced by their demographic characteristics or their attitudes, it is therefore important to consider these factors when implementing a potential policy. In our study, visitors' income, education, employment conditions, and management concerns were the most important variables in the CE model.

\subsection{Willingness to Pay Estimation}

Marginal values were estimated by dividing the coefficient of each attribute by the coefficient of price. The results of marginal WTP is presented in the last (rightmost) column of Table 6. Estimated marginal values for various attributes were estimated for hypothetical improvement from current condition to level two and three of each attribute. Results showed that PI3 and EM3 received highest value.

Once these parameters are estimated, welfare measures for a desired change in national park management can be calculated. Welfare measures are particularly beneficial for policy purposes with estimating changes in welfare associated with a particular policy [48]. Using Hanemann's method, welfare measure is represented by following formula:

$$
\mathrm{CS}=1 / \alpha\left[\ln \Sigma \exp \left(\mathrm{V}_{i} 1\right)-\ln \Sigma \exp \left(\mathrm{V}_{i} 0\right)\right]=-1 / \beta_{\mathrm{CV}}\left(\mathrm{V}_{i} 1-\mathrm{V}_{i} 0\right)
$$

In estimating the related utility following Hensher et al., 2005 [39], distributional assumptions related to random parameters were considered. The welfare measure for improvement in management of PNP against status quo is estimated at about MYR 9. The optimal rate in this study was determined by PNP management, based on perspectives of the majority of visitors to prevent any disproportionate 
effect on low-income citizens or other social groups. Therefore, the study suggests that the optimal entrance fee of MYR 10 (for year 2014) would be accepted by most visitors and would maximize PNP overall revenue, as well. Aggregate results were obtained by multiplying the estimated WTP with the number of annual visitors. The findings show that the net economic value of the PNP would have been about MYR 1,082,760 (US\$ 338,362) in 2012. This estimated amount can be increased by growth in the number of visitors and by imposing a larger admission fee.

\section{Discussion of the Results}

According to SEM results, the importance of national parks and approaches to improve management and tourism activities in the PNP are strongly related. This indicates that people's appreciation of the national park and their awareness about value of the park is a prerequisite for growing concerns about management and tourism improvement and, conversely, concerns about management improvement and meeting tourists' expectations promote and facilitate people's appreciation and awareness. The results have special importance for PNP management since they suggest that park visitor satisfaction is, on average, increased through the provision of informational resources that inform their experiences. The PNP managers also need to specify necessary programmes that engage visitors in contemplative experiences and ensure the long-term efficiency of sustainable environmental behaviors. As people get more opportunities to be involved in park-related issues, they change from passive visitors to active visitors that care about management of the park and other visitors' behavior. The significant effect of education on latent variables indicated that persons with higher education have more positive attitudes about the value of PNP and are more concerned about seeing improvements in management and the tourism facilities in PNP.

The results of the choice experiment showed that respondents also valued the PNP proposed management scenarios highly. This emphasizes respondents' expectations for park managers to move away from the current condition of the park by providing better management alternatives. Accordingly, variables EM2 and EM3 were positive in accordance to prior expectations and significant at the 1\% level. This means improvement in ecological management of the PNP to the satisfied and very good level is preferred to the current condition level. This result is in agreement with earlier findings (e.g., $[3,49,50])$, showing that better biodiversity conservation and environmental protection contributed to increases in overall utility for the respondents.

Level 2 and level 3 of recreational facilities were significant at the 5\% and $1 \%$ levels, respectively, with an expected positive sign. The lack of facilities and their quality (such as cleanliness) results in complaints from visitors. Waste disposal especially affects the beauty of beaches in PNP and makes it undesirable to visitors. Therefore, the positive sign of this attribute implies that visitors are willing to pay to improve the basic recreational facilities of PNP. Similarly, previous studies showed that the quality and quantity of facilities such as washrooms, camping and picnic areas, and suitable beach areas can affect experiences and satisfaction among visitors [13].

Providing information directly to the visitors may be their only opportunity to learn about the ecological importance of these protected areas in harmoniously balancing relationships between plant and animal species in nature. Hence, an effective and enlightening approach explaining and interpreting the park to the visitors can contribute to sustaining waves of tourists by educating them 
about what they are seeing and experiencing, assisting them in minimizing their potentially negative impacts, and encouraging those activities which ensure ongoing maintenance of the quality of the environment. Accordingly, variables PIS2 and PIS3 (provision of information) were significant at the $5 \%$ and $1 \%$ levels, respectively, with an expected positive sign. The positive sign means that visitors are concerned about information and priorities education. The results are consistent with $[3,5,17,51]$, in that they confirmed that interpretation and information provision is favored by visitors who had been interviewed. The cost variable (CC) which was offered as possible entrance fee was significant at the $5 \%$ level with an expected negative sign. Visitors prefer those programs that do not require any additional cost. Thus, the sign of the payment coefficient was negative, which indicated the effect on utility of choosing a choice set with a high payment level, as expected.

The interactions between income and employment with level 3 recreational facilities, education with improvement in ecological management of PNP, and provision of information were significant and positive. This implies that persons with higher income and higher education who are currently employed were more concerned about improvement in management and conservation of PNP.

This result seems reasonable since a higher level of education and income could be related to a better understanding of the problem and greater ability to pay. The positive relationship between these variables is generally supported by the literature. For example [16,50,52-55] indicated that highly educated people and those with higher income are more supportive of nature preservation and have higher WTP.

The positive relationship between perception of improvement in PNP management and EM3 (level 3 of Ecological Management) was significant at the $1 \%$ level with an expected positive sign. This means that people with high appreciation and knowledge about PNP and more concern about improvement in park management have higher WTP.

Marginal willingness to pay estimation indicated the high value of provision of information between respondents, as most of them visit the park with their families or with educational groups. Hence, they appreciate the provision of information about PNP. Results also showed that visitors preferred more adequate management of the park's ecological and biological aspects. This quantitative information about visitors' preferences can help park managers and policy makers decide about future park programs [56] and also possibly introduce an entrance fee as a revenue stream to fund park upkeep and improvement. Introducing and collecting an entrance fee can provide the park with additional income beyond what the government budgets. The revenue generated from tourists who value the ecosystem for its inherent qualities can be used to support the values of selected tourists, to protect biodiversity and ecological integrity, mitigate environmental problems, employ educated guards and tour guides, and enhance public education programs. Also, benefits from strengthened park management could strengthen local communities whose members could participate in park activities, and as a result, this helps to enhance quality of life for local residents.

The estimated WTP amount in this study is generally equal to other Malaysian protected areas. For example, in addition to PNP, entry is currently free for Malaysia's National Elephant Conservation Center and the Tasek Bera Ramsar Site. While the entrance fee for foreign visitors to some national parks such as Taman Negara Kelantan, Taman Negara Pahang, and Taman Negara Terengganu is $\$ 3.33$ per visitor, the estimated entrance fee is lower than other developing countries such as Thailand, Nepal, Costa Rica, or Ecuador. Taking into account the fact that the number of visitors to the national 
parks (with low entrance fee) is relatively low compared to total visitors, other policy instruments such as a departure green tax could be considered in countries such as Malaysia,.

In our study, the point and cross elasticity measurement between alternatives gave us the opportunity to predict how likely tourists would react to any future change in the entrance fee. In simple terms, elasticity measures the relationship between percentage change of variable (or program) and percentage change in quantity demanded, ceteris paribus [39].

Based on our findings, a $1 \%$ increase in the entrance fee will decrease the probability of selecting option 1 and option 2 management alternatives each by $0.6 \%$. However, the price elasticity for the option 1 alternative is relatively inelastic. Therefore, overall results suggest that improving management along with imposing any admission fee above zero up to MYR 10 would increase PNP revenue. Since aggregated revenue can be estimated from price multiplied by the number of likely visitors, a $10 \%$ increase in entrance fee should increase revenue by about $4.5 \%$ (we assumed MYR 1 as the baseline price).

A simulation method in Nlogit5 was used to estimate a "what-if" scenario. The selected scenario assumed imposing an admission fee of MYR10 (compared to zero, or no entrance fee at the moment). Imposing an RM10 entrance fee would produce an estimated market share of $47.43 \%$ (down from $48.9 \%$ ) and $49.05 \%$ (down from 50.17\%) for option 1 and option 2 alternatives, respectively. These two options propose better management of PNP. The same change would produce a market share of $3.51 \%$ (up from $0.93 \%$ ) for the status quo. This means that increasing the entrance fee from zero (reflecting the status quo) to RM10, decreases the share of options which contain or involve better park management (namely option 1 and option 2) by $1.45 \%$ and $1.12 \%$ respectively. Since these two improvement options are unlabeled, it implies that $2.57 \%$ (26) of the original choices for these alternatives will prefer the status quo option of "no management improvement" with zero entrance fees. Findings also indicated that for any improvement in the management of PNP, imposing an admission fee of MYR10 will result in almost 96\% market share of these alternatives compared to the status quo. Based on Malaysian GDP growth, the income increment is around $4.5 \%$ per year. Therefore, we calculated a $5 \%$ annual price and simulated the results for 5 years. Our results demonstrated that under the $5 \%$ price increment scenarios, the decline in original choices will be $0.8 \%$ each year. Considering this and improvement in management along with awareness could be a useful tool to determine possible future revenue amounts based on the distribution of incomes in likely tourists.

\section{Conclusions}

Malaysia's tourism vision involves making the industry a primary source of national revenue and a major contributor to the socio-economic development of the nation. The tourism sector has great potential for contributing numerous financial benefits, directly or indirectly. It helps generate growth and development for a nation, job opportunities, foreign exchange earnings, and government revenue.

The present study utilized a choice experiment as one feasible approach to analyze users' preferences for improving the management of PNP for the dual purposes of conservation and recreation. The results of the study revealed that visitors prefer improvement in PNP management. These results demonstrated that the expectations of tourists are more likely to be fulfilled when there is 
improvement in the ecological conditions of the park. This is in addition to their desire for readilyavailable information on primary recreational facilities. In general, more than $86 \%$ of respondents selected one condition above the current situation of PNP. The survey respondents expressed the highest value and preference for very good ecological management of park, with efforts to provide more information about its valuable flora and fauna, sensitive areas, and the characteristics of its habitats.

The results of this study can contribute to better-informed decisions for two levels of managers and regional planners. First, park managers need to more robustly understand how nature-based tourism can educate a broader and more socioeconomically diverse base of prospective tourists. Second, the longer-term ecological goals of conservation require implementing sustainability principles, and national park managers must integrate all of these understandings with their current projects and the continuous improvement of their management practices. Important conservation and development decisions can be made by considering users' preferences and perceptions. Third, estimated marginal value, which is expressed as an entrance fee and used in trade-off between improved attributes of the park, can reflect the discovery that the park can consider the introduction of an entrance fee. In light of limited budget allocations from the national government, this additional revenue could help fund improved management of the park. It is worth noting that, since demand for ecotourism is usually unpredictable and unstable, it is better to consider entry fees as a "supplementary" source of revenue to government funding and not a "replacement" for it [11]. The successful management of PNP and its development are highly dependent on visitors' satisfaction with its resources. From the visitors' perspective, better park conservation will improve their aesthetic appreciation and enhance their experience and satisfaction from the park [13]. Application of a choice experiment which enables decision-makers to estimate visitor WTP for each particular level of improvement could help park managers focus and schedule their development and management efforts. Since the main aim of establishing national parks is the preservation of sensitive habitats and biodiversity, introducing an admission fee could help the managers concentrate on effectively managing the park rather than on building mass tourism, from which increased congestion would increase stresses on the ecosystems they are trying to protect.

This study results suggests an admission fee of MYR 10 (USD 3.3) for PNP (based on 2013 prices). However, in the sample composition, the proportion of foreign visitors was small. This did not permit the estimation of stratum-specific models. Therefore, in future studies, a sufficient number of domestic and foreign visitors could be targeted to produce better information on the willingness to pay of this group of visitors. Hence, a two-tier charging system would be more efficient. Applying more efficient designs rather than an orthogonal main effect design and more advanced methods to model heterogeneity in preference of visitors could also lead to more realistic and useful results, which our study was unable to consider because of funding constraints.

\section{Acknowledgments}

The authors thank the Department of Wildlife and National Parks Malaysia, Penang National Park staff, and all the respondents who kindly participated and responded to the questions. The authors also 
would like to thank the editors and two anonymous reviewers for their valuable comments on the manuscript.

\section{Author Contributions}

Alias Radam, Mohd Rusli Yacob and Nor Hanim Nordin contributed to research design, questionnaire design and administration and data collection. Sara Kaffashi contributed to data analysis and writing the paper.

\section{Conflict of Interest}

The authors declare no conflict of interest.

\section{References}

1. Liu, C.; Xiao, W.; Li, J.; Pechacek, P. Attitude of tourists visiting nature reserves in China. Tour. Manag. Perspect. 2013, 5, 1-4.

2. Hein, L. Economic benefits generated by protected areas: The case of the Hoge Veluwe forest, the Netherlands. Ecol. Soc. 2011, 16, 13.

3. Juutinen, A.; Mitani, Y.; Mäntymaa, E.; Shoji, Y.; Siikamäki, P.; Sventom, R. Combining ecological and recreational aspects in national park management: A choice experiment application. Ecol. Econ. 2011, 70, 1231-1239.

4. Journey Malaysia. http://www.journeymalaysia.com/islandpenangtrekking_map.htm (accessed on 10 November 2014).

5. Hearne, R.R.; Salinas, Z.M. The use of choice experiments in the analysis of tourist preferences for ecotourism development in Costa Rica. J. Environ. Manag. 2002, 65, 153-163.

6. Hamzah, A. Managing the Impact of Visitors to Protected Areas in Malaysia: Success Stories \& New Challenges. Conference Proceedings of the International Workshop on Governance in Asian Protected Areas: Follow-up on the Aichi Target (Post 2010 Target) and Protected Areas Decision from the CBD/COP 10, Akita, Japan, 8-11 January 2010.

7. Turner, R.W. Using Contingent Choice Surveys to inform national park management. J. Environ. Stud. Sci. 2013, 3, 120-138.

8. Theodori, G.L.; Luloff, A.E.; Willits, F.K. The Association of Outdoor Recreation and Environmental Concern: Reexamining the Dunlap-Heffernan Thesis1. Rural Sociol. 1998, 63, 94-108.

9. Zaradic, P.A.; Pergams, O.R.; Kareiva, P. The impact of nature experience on willingness to support conservation. PLoS ONE 2009, 4, e7367.

10. Mansourian, S.; Dudley, N. Public Funds to Protected Areas; WWF International: Gland, Switzerland, 2008.

11. Reynisdottir, M.; Song, H.; Agrusa, J. Willingness to pay entrance fee to natural attractions: An Icelandic case study. Tour. Manag. 2008, 29, 1076-1083.

12. Shahabuddin, Gh. Dynamics between protected areas and economic use. 2009. Available online: http://www.fao.org/docrep/011/i0627e/I0627E10.htm (accessed on 22 July 2014). 
13. Loomis, J.; Santiago, L. Economic Valuation of Beach Quality Improvements: Comparing Incremental Attribute Values Estimated from Two Stated Preference Valuation Methods. Coast. Manag. 2013, 41, 75-86.

14. Yacob, M.R.; Radam, A.; Shuib, A. A contingent valuation study of marine parks ecotourism: The case of Pulau Payar and Pulau Redang in Malaysia. J. Sustain. Dev. 2009, 2, 95.

15. Ahmad, A.S. Visitors' Willingness to Pay for an Entrance Fee: A Case Study of Marine Parks in Malaysia. PhD Thesis. Department of Economics, Faculty of Law, Business and Social Science, University of Glasgow, 2009.

16. Han, S.Y.; Lee, C.K.; Mjelde, J.W.; Kim, T.K. Choice-experiment valuation of management alternatives for reintroduction of the endangered mountain goral in Woraksan National Park, South Korea. Scand. J. For. Res. 2010, 25, 534-543.

17. Lindberg, K.; Veisten, K. Local and non-local preferences for nature tourism facility development. Tour. Manag. Perspect. 2012, 4, 215-222.

18. Tratalos, J.A.; Sugden, R.; Bateman, I.J.; Gill, J.A.; Jones, A.P.; Showler, D.A.; Watkinson, A.R. The conflict between conservation and recreation when visitors dislike crowding: A theoretical and empirical analysis of the spatial distribution of recreational beach users. Environ. Resour. Econ. 2013, 55, 447-465.

19. Cerda, C.; Losada, T. Assessing the value of species: A case study on the willingness to pay for species protection in Chile. Environ. Monit. Assess. 2013, 185, 10479-10493.

20. Wuepper, D. A Recreational Demand Model for Jasmund National Park: Taking into Account Anchoring and Averaging Bias. In Proceedings of the 20th Annual Conference of the European Association of Environmental and Resource Economists (EAERE) Toulouse, France, 26-29 June 2013.

21. Vincent, J.R.; Carson, R.T.; DeShazo, J.R.; Schwabe, K.A.; Ahmad, I.; Chong, S.K.; Potts, M.D. Tropical countries may be willing to pay more to protect their forests. Proc. Natl. Acad. Sci. USA 2014, 111, 10113-10118.

22. Czajkowski, M.; Budziński, W.; Campbell, D.; Giergiczny, M.; Hanley, N. Spatial Heterogeneity of Willingness to Pay for Forest Management; Available online: ftp://188.128.204.246/ spatial_WP.pdf. (accessed on 10 March 2015).

23. Mayer, M. Can nature-based tourism benefits compensate for the costs of national parks? A study of the Bavarian Forest National Park, Germany. J. Sustain. Tour. 2014, 22, 561-583.

24. Chan, N.W. Issues and challenges of managing natural heritage in Penang National Park, Malaysia. Badaruddin Mohamed \& Morshidi Sirat. In Proceedings of the 2nd National Symposium on Tourism Research-Theories \& applications, Penang, Malaysia 18 July 2009; pp. 111-123.

25. Hong, C.W.; Chan, N.W. The potentials, threats and challenges in sustainable development of Penang National Park. Malays. J. Environ. Manag. 2010, 11, 95-109.

26. Laws Of Malaysia Act 226 National Parks Act 1980. Available online: http://www. agc.gov.my/Akta/Vol.\%205/Act\%20226.pdf (accessed on 20 February 2014).

27. Samdin, Z.; Aziz, Y.A. The Role of Socio-demographic and Economics on Ecotourism Activities at the Penang National Park, Malaysia: A Services Marketing Perspective. In Proceedings of The 2nd International Research Symposium in Service Management Yogyakarta, Indonesia, 26-30 July 2011. 
28. Addo-Fordjour, P.; Rahmad, Z.B.; Shahrul, A.M.S. Effects of human disturbance on liana community diversity and structure in a tropical rainforest, Malaysia: Implication for conservation. J. Plant Ecol. 2012, 5, 391-399.

29. Morrison, M.; Bennett, J. Valuing New South Wales Rivers for use in benefit transfer. Aust. J. Agric. Resour. Econ. 2004, 48, 591-611.

30. Amalia, M. Designing a Choice Modelling Survey to Value the Health and Environmental Impacts of Air Pollution from the Transport Sector in the Jakarta Metropolitan Area (No. rr2010111). Economy and Environment Program for Southeast Asia (EEPSEA), 2010.

31. Weber, M.A.; Stewart, S. Public values for river restoration options on the Middle Rio Grande. Restor. Ecol. 2009, 17, 762-771.

32. Arrow, K.; Solow, R.; Portney, P.R.; Leamer, E.E.; Radner, R.; Schuman, H. Report of the NOAA Panel on Contingent Valuation. Fed. Regist. 1993, 58, 4601-4614.

33. Mitchell, R.C.; Carson, R.T. Using Surveys to Value Public Goods: The Contingent Valuation Method; Resource for the Future: Washington, DC, USA, 1989. p. 225.

34. Greene, W.H.; Hensher, D.A. A latent class model for discrete choice analysis: Contrasts with mixed logit. Transp. Res. Part B: Methodol. 2003, 37, 681-698.

35. Birol, E.; Cox, V. Using choice experiments to design wetland management programmes: The case of Severn Estuary Wetland, UK. J. Environ. Plan. Manag. 2007, 50, 363-380.

36. Thurstone, L.L. The method of paired comparisons for social values. J. Abnorm. Soc. Psychol. $\mathbf{1 9 2 7 ,} 21,384$.

37. McFadden, D. The measurement of urban travel demand. J. Public Econ. 1974, 3, 303-328.

38. Lancaster, K.J. A new approach to consumer theory. J. Polit. Econ. 1966, 74, 132-157.

39. Hensher, D.A.; Rose, J.M.; Greene, W.H. Applied Choice Analysis: A Primer; Cambridge University Press: New York, NY, USA, 2005.

40. Hensher, D.A.; Rose, J.; Greene, W.H. The implications on willingness to pay of respondents ignoring specific attributes. Transportation 2005, 32, 203-222.

41. Maier, R. Knowledge Management Systems: Information and Communication Technologies for Knowledge Management; Springer: Berlin-Heidelberg, Germany, 2002.

42. Voon, B.H. Service environment of restaurants: Findings from the youth customers. J. ASIAN Behavioural. Stud. 2011, 1, 45-56.

43. Tang, J.; Folmer, H.; Xue, J. Estimation of awareness and perception of water scarcity among farmers in the Guanzhong Plain, China, by means of a structural equation model. J. Environ. Manag. 2013, 126, 55-62.

44. Hess, S.; Beharry-Borg, N. Accounting for latent attitudes in willingness-to-pay studies: The case of coastal water quality improvements in Tobago. Environ. Resour. Econ. 2012, 52, 109-131.

45. Muhammad-Sukki, F.; Munir, A.B.; Ramirez-Iniguez, R.; Abu-Bakar, S.H.; Yasin, S.H.M.; McMeekin, S.G.; Stewart, B.G. Solar photovoltaic in Malaysia: The way forward. Renew. Sustain. Energy Rev. 2012, 16, 5232-5244.

46. Jöreskog, K.G.; Sörbom, D.; Du Toit, S.H.C. LISREL 8: New Statistical Features; Scientific Software International: Lincolnwood, IL, USA, 2000.

47. Toma, L.; Mathijs, E. Environmental risk perception, environmental concern and propensity to participate in organic farming programmes. J. Environ. Manag. 2007, 83,147-157. 
48. Kjær, T. A review of the discrete choice experiment-with emphasis on its application in health care. Syddansk Universitet: Odense, Denmark, 2005.

49. Kaffashi, S.; Shamsudin, M.N.; Radam, A.; Yacob, M.R.; Rahim, K.A.; Yazid, M. Economic valuation and conservation: Do people vote for better preservation of Shadegan International Wetland? Biol. Conserv. 2012, 150, 150-158.

50. Wang, P.W.; Jia, J.B. Tourists' willingness to pay for biodiversity conservation and environment protection, Dalai Lake protected area: Implications for entrance fee and sustainable management. Ocean Coast. Manag. 2012, 62, 24-33.

51. Moscardo, G. Interpretation and Sustainable Tourism. J. Tour. Stud. 1998, 9, 2-13.

52. Naidoo, R.; Adamowicz, W.L. Biodiversity and nature-based tourism at forest reserves in Uganda. Environ. Dev. Econ. 2005, 10, 159-178.

53. Westerberg, V.H.; Lifran, R.; Olsen, S.B. To restore or not? A valuation of social and ecological functions of the Marais des Baux wetland in Southern France. Ecol. Econ. 2010, 69, 2383-2393.

54. Ghosh, P,K.; Mondal, M,S. Economic valuation of the non-use attributes of a south-western coastal wetland in Bangladesh. J. Environ. Plan. Manag. 2012, 56, 1403-1418.

55. Kreye, M.M.; Adams, D.C.; Escobedo, F.J. The Value of Forest Conservation for Water Quality Protection. Forests 2014, 5, 862-884.

56. Adams, D.C.; Bwenge, F.; Lee, D.J.; Larkin, S.; Alavalapati, J.R.R. Public Preferences for Controlling Upland Invasive Plants in State Parks: Application of Choice Model. For. Policy Econ. 2011, 13, 465-472.

(C) 2015 by the authors; licensee MDPI, Basel, Switzerland. This article is an open access article distributed under the terms and conditions of the Creative Commons Attribution license (http://creativecommons.org/licenses/by/4.0/). 